\title{
Research Parameters of Combined Processing for Producing Ligature Rods from Alloy System Al-Ti-B
}

\author{
Sergey B. Sidelnikova, \\ Denis S. Voroshilov*a, Aleksey A. Startsev ${ }^{\mathrm{b}}$, \\ Angelina A. Kovaleva ${ }^{a}$, Yekaterina S. Lopatina ${ }^{a}$, \\ Roman I. Galiyev and Nikita A. Zudin ${ }^{\mathrm{a}}$ \\ ${ }^{a}$ Siberian Federal University \\ 79 Svobodny, Krasnoyarsk, 660041, Russia \\ ${ }^{b} U C$ «RUSAL», Department of Finished Products \\ 40 Pogranichnikov Str., Krasnoyarsk, 660111, Russia
}

Received 28.04.2015, received in revised form 13.05.2015, accepted 26.05.2015

This article represents research results patterns of change mechanical properties and energypower parameters of processing during obtaining ligature rods from alloy system Al-Ti-B using methods of combined rolling-extruding and combined casting and rolling-extruding.

Keywords: combined processes, rolling, extruding, energypower parameters, mechanical properties, aluminium.

DOI: $10.17516 / 1999-494 X-2015-8-5-646-654$.

(C) Siberian Federal University. All rights reserved

* Corresponding author E-mail address: d.s.voroshilov@gmail.com 


\title{
Исследование параметров совмещенной обработки
}

\section{Для получения лигатурных прутков}

\section{из сплавов системы Al-Ti-B}

\author{
С.Б. Сидельников ${ }^{\mathrm{a}}$, Д.С. Ворошилов ${ }^{\mathrm{a}}$, \\ А.А. Старцев ${ }^{\sigma}$, А.А. Ковалева ${ }^{a}$, \\ Е.С. Лопатина ${ }^{a}$, Р.И. Галиев ${ }^{a}$, Н.А. Зудин ${ }^{a}$ \\ ${ }^{a}$ Сибирский федеральный университет \\ Россия, 660041, Красноярск, пр. Свободный, 79 \\ ${ }^{\sigma}$ ОК «РУСАЛ», Департамент готовой продукичи \\ Россия, 660111, Красноярск, ул. Пограничников, 40
}

\begin{abstract}
В статье представлены результаты исследований закономерностей изменения механических свойств и энергосиловых параметров обработки при получении лигатурных прутков из сплава системы Al-Ti-B с помощуью методов совмещенной прокатки-прессования и совмещенного литья и прокатки-прессования.
\end{abstract}

Ключевые слова: совмещуенные процессы, прокатка, прессование, энергосиловые параметры, механические свойства, алюминий.

Сплавы системы Al-Ті-В широко применяются для производства лигатурных прутков, необходимых для модифицирования слитков из алюминиевых сплавов. Ввод данной лигатуры приводит к улучшению механических свойств и уменьшению газовой пористости. Она применима как для алюминия, так и для всех алюминиевых сплавов - деформируемых и литейных. Область использования данной лигатуры достаточно обширна: это производство слитков для последующей экструзии, фольги, ответственных корпусных отливок в кокиль и песчаные формы. Лигатурные прутки могут применяться во всех типах плавильных агрегатов, разливочных ковшей и миксеров, поскольку ими можно не только обрабатывать весь объем расплава в печи или ковше, но и вести обработку расплава в струе, потоке или кристаллизаторах. Потребность в таком виде продукции достаточно большая, так как практически все производимые с помощью литья сплавы в России и за рубежом модифицируются для измельчения литой структуры. Кроме того, к стандартному оборудованию современных литейных систем для производства алюминиевых слитков относится дозировочная машина для непрерывной подачи прутка AlТі-В из бухты (измельчающей зерно присадки) в находящийся в литейном желобе расплав [1]. Изделия из этих сплавов прессуются удовлетворительно, но крайне тяжело обрабатываются методами обычной прокатки, так как склонны к растрескиванию при возникновении растягивающих напряжений.

В настоящее время металлургическая промышленность в России испытывает острую потребность в лигатурных прутках из сплавов системы Al-Ti-B, основная часть которых производится за рубежом. Изготовление деформированных полуфабрикатов из этих сплавов прессованием на горизонтальных прессовых установках возможно, но неэффективно, поскольку они трудно поддаются обработке (нетехнологичны), а энергозатраты при этом довольно значительны. Возникновение и развитие способов непрерывного прессования, основанных на использова-

$$
\text { - } 647 \text { - }
$$


нии активных сил трения, дало новый импульс развитию технологии обработки алюминиевых сплавов за счет замены мощных гидравлических прессов на достаточно компактные установки типа Конформ. Однако эти установки также имеют электродвигатели большой мощности (200 кВт и выше) и используются в основном для обработки металла с небольшими степенями деформации. Кроме того, неравномерность деформации, вызванная наличием реактивных сил трения по неподвижному инструменту, не дает возможности получить требуемый уровень и равномерное распределение механических свойств по длине длинномерного полуфабриката. В этой связи за рубежом лигатурные прутки производятся на литейно-прокатных агрегатах, а технология их производства характеризуется высокой энерго- и трудоемкостью. Дальнейшее развитие идеи использования сил трения для деформирования была воплощена в процессах, совмещающих процесс прокатки и прессования в одном очаге деформации (метод СПП) [2]. Длинномерная нагретая заготовка при этом задается в закрытый калибр валков прокатного стана, перекрытый на выходе матрицей с отверстием заданной формы и размеров (рис. 1) [3].

В этих процессах можно использовать заготовки, полученные по различным технологиям литья, в том числе и с использованием электромагнитного кристаллизатора. Проведенные исследования показали, что применение литья в электромагнитный кристаллизатор и последующей прокатки-прессования, характеризующейся высокой интенсивностью деформации, позволяет обрабатывать в том числе и труднодеформированные алюминиевые сплавы [4]. При этом энергозатраты на выдавливание металла через калибрующее отверстие матрицы за счет использования активных сил трения, подводимых валками, в 2-4 раза ниже, чем на установках Конформ, и в 5-10 раз ниже по сравнению с традиционными технологиями дискретного прессования и непрерывного литья-прокатки. Кроме того, выход годного может достигать 90-95 \%, что ведет к снижению расхода металла и себестоимости пресс-изделий.

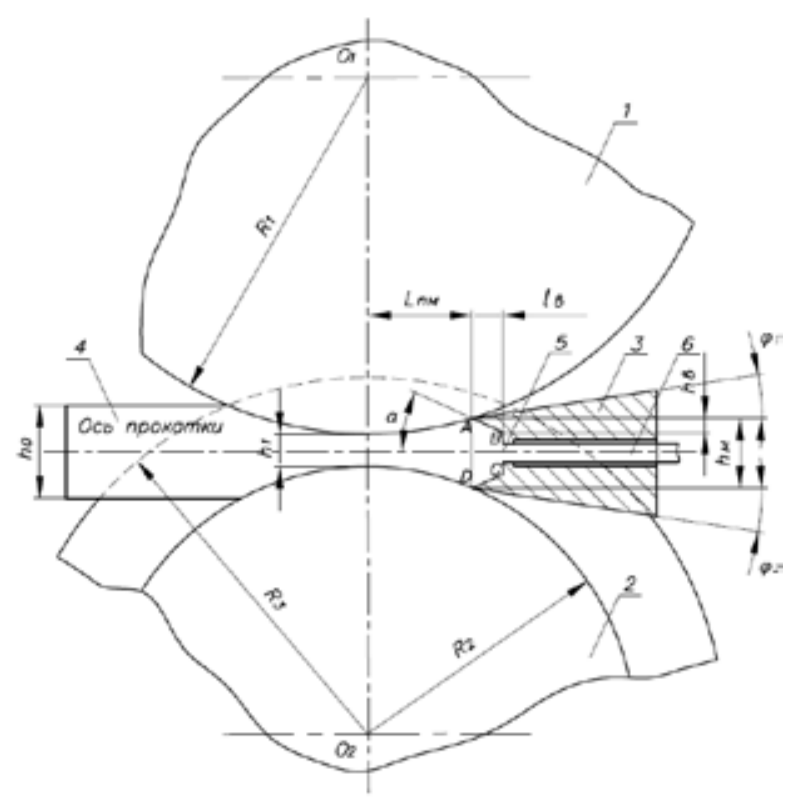

Рис. 1. Устройство СПП по патенту РФ № 138590: 1 - валок с выступом; 2 - валок с вырезом; 3 - матрица; 4 - заготовка; 5 - зона выдавливания металла; 6 - пресс-изделие 


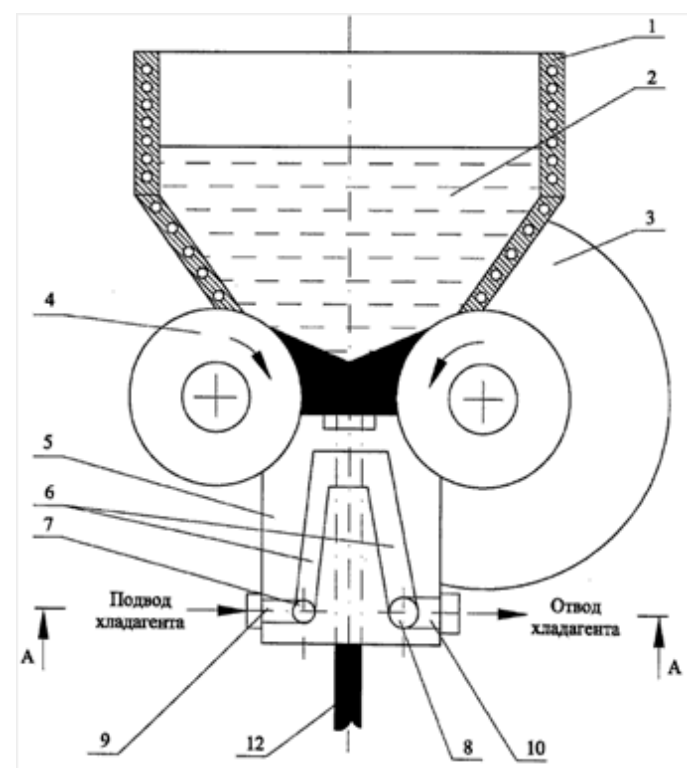

Рис. 2. Общий вид устройства СЛиПП по патенту РФ № 2486027: 1 - печь-миксер; 2 - расплав металла; 3, 4 - валки; 5 - матрица; 6, 7, 8 - охлаждаемые каналы; 9 - каналы для подвода хладагента; 10 - каналы для отвода хладагента; 11 - пластины; 12 - пресс-изделие

Еще более эффективным с позиций энергосбережения является метод совмещенного литья и прокатки-прессования (СЛиПП), когда расплав металла заливается во вращающиеся валки установки (рис. 2) и обрабатывается с помощью совмещенной прокатки-прессования [5]. Данный метод позволяет исключить из технологии передел получения литой заготовки и сократить состав оборудования.

Целью данных исследований, таким образом, является инженерная оценка обрабатываемости [6] сплавов системы Al-Ti-B и создание энергоэффективной технологии получения лигатурного прутка для модифицирования алюминиевых сплавов с использованием совмещенных методов обработки металлов давлением. Так как применялась стандартная лигатура AlTi5B1, задача оценки модифицирующей способности полученных прутков не ставилась.

Исследования проводили на установке совмещенной обработки СПП-200 [2], смонтированной на базе прокатного стана с диаметром валков 200 мм, включающего электродвигатель переменного тока мощностью 20 КВт, коробку передач, двухступенчатый редуктор с передаточным числом $i=40$ и максимальным моментом на выходном валу 10 кН×м, шестеренную клеть и прокатную клеть, которая для удобства загрузки заготовок (при СПП) или подачи расплава (при СЛиПП) в калибр была повернута на угол $90^{\circ}$ и установлена на опору. С помощью установки получали прутки диаметром 5, 7 и 9 мм методами СПП и СЛиПП из сплава системы Al-Ti-В с содержанием титана 4,85 \% и бора 1,01 \%. Для планирования экспериментальных исследований по определению энергосиловых параметров совмещенных процессов для исследуемого сплава была разработана матрица факторного эксперимента. Изменяемыми факторами для данных сплавов являлись следующие параметры: температура нагрева заготовки $T_{3}=550$ и $580{ }^{\circ} \mathrm{C}$ (для процесса СЛиПП - температура расплава $T_{\text {расnл }}=750$ и $780{ }^{\circ} \mathrm{C}$ ); скорость деформа- 
ции $\xi=0,74$ и 1,49 $\mathrm{c}^{-1}$; коэффициент вытяжки $\mu=5,2$ (диаметр прутка 9 мм), 8,6 (диаметр прутка 7 мм) и 16,8 (диаметр прутка 5 мм). Для определения энергосиловых параметров применяли кольцевые мездозы, установленные под нажимные винты и матрицу, подключенные к регистрирующей аппаратуре, в качестве которой использовалась тензостанция Zet017-T8 фирмы ZetLAB (Россия). Для измерения применяли датчики CWW-50tf и CWW-100tf фирмы Dacell Co. LTD (Южная Корея) с максимально допустимым усилием сжатия 500 кН и 1 MH соответственно. С помощью данной тензометрической аппаратуры были определены энергосиловые параметры изучаемых процессов (усилие, действующее на валки $P_{6}$, и усилие, действующее на матрицу $P_{m}$ ) и получены зависимости этих усилий от варьируемых параметров. Результаты эксперимента представлены в табл. 1.

Анализ полученных данных показал, что энергосиловые параметры процесса СПП выше, чем процесса СЛиПП. Как видно из экспериментальных данных, приведенных в табл. 1, силы на валках и матрице увеличиваются с ростом коэффициента вытяжки, что является результатом увеличения объема деформируемого металла с повышением степени деформации по мере заполнения калибра. Анализ энергосиловых параметров показал также, что с увеличением температуры нагрева заготовки, силы на валках и матрице уменьшаются, что соответствует общепринятым законам теории ОМД.

С увеличением скорости деформации на сопротивление деформации влияют два фактора: оно может увеличиваться за счет деформационного упрочнения или уменьшаться за счет деформационного разогрева и снижения теплоотдачи в инструмент с ростом температуры обрабатываемого металла и уменьшением времени контакта заготовки с валками. При проведении опытов было установлено, что процессы разупрочнения с ростом температуры деформационного разогрева являются преобладающими по сравнению с упрочнением, поэтому силовые параметры уменьшаются с увеличением скорости деформации. Усилия, действующие

Таблица 1. Результаты экспериментальных исследований энергосиловых параметров процессов СПП и СЛиПП для исследуемого сплава системы Al-Ti-B

\begin{tabular}{|c|c|c|c|c|c|c|c|}
\hline \multirow{3}{*}{$\begin{array}{c}\text { Скорость } \\
\text { деформации, с-1 }\end{array}$} & \multirow{3}{*}{ Усилия, кН } & \multicolumn{6}{|c|}{ СПП } \\
\hline & & \multicolumn{3}{|c|}{$\mathrm{T} 3=550{ }^{\circ} \mathrm{C}$} & \multicolumn{3}{|c|}{$\mathrm{T} 3=580^{\circ} \mathrm{C}$} \\
\hline & & $\mu=16,8$ & $\mu=8,6$ & $\mu=5,2$ & $\mu=16,8$ & $\mu=8,6$ & $\mu=5,2$ \\
\hline \multirow{2}{*}{$\xi=0,74$} & Рв & 167 & 110 & 90 & 93 & 86 & 82 \\
\hline & $\mathrm{PM}_{\mathrm{M}}$ & 265 & 210 & 191 & 204 & 196 & 186 \\
\hline \multirow{5}{*}{$\xi=1,49$} & Рв & 119 & 81 & 77 & 90 & 77 & 68 \\
\hline & $\mathrm{PM}_{\mathrm{M}}$ & 215 & 199 & 154 & 199 & 186 & 121 \\
\hline & & \multicolumn{6}{|c|}{ СЛиПП } \\
\hline & & \multicolumn{3}{|c|}{ Траспл $=750{ }^{\circ} \mathrm{C}$} & \multicolumn{3}{|c|}{ Траспл $=780^{\circ} \mathrm{C}$} \\
\hline & & $\mu=16,8$ & $\mu=8,6$ & $\mu=5,2$ & $\mu=16,8$ & $\mu=8,6$ & $\mu=5,2$ \\
\hline \multirow{2}{*}{$\xi=0,74$} & Рв & 85 & 71 & 63 & 75 & 60 & 53 \\
\hline & $\mathrm{PM}_{\mathrm{M}}$ & 240 & 210 & 189 & 189 & 174 & 168 \\
\hline \multirow{2}{*}{$\xi=1,49$} & Рв & 58 & 54 & 50 & 54 & 52 & 49 \\
\hline & $P_{M}$ & 196 & 178 & 168 & 183 & 166 & 153 \\
\hline
\end{tabular}


Таблица 2. Результаты механических испытаний прутков из исследуемого сплава системы Al-Ti-B, полученных различными методами совмещенной обработки

\begin{tabular}{|c|c|c|c|c|c|c|c|}
\hline \multirow{3}{*}{$\begin{array}{c}\text { Скорость } \\
\text { деформации, } \mathrm{c}^{-1}\end{array}$} & \multirow{3}{*}{$\begin{array}{c}\text { Мех. } \\
\text { свойства }\end{array}$} & \multicolumn{6}{|c|}{ СПП } \\
\hline & & \multicolumn{3}{|c|}{$T_{3}=550{ }^{\circ} \mathrm{C}$} & \multicolumn{3}{|c|}{$T_{3}=580^{\circ} \mathrm{C}$} \\
\hline & & $\mu=16,8$ & $\mu=8,6$ & $\mu=5,2$ & $\mu=16,8$ & $\mu=8,6$ & $\mu=5,2$ \\
\hline \multirow{2}{*}{$\xi=0,74$} & $\sigma_{\mathrm{B}}, \mathrm{MПа}$ & 213 & 191 & 153 & 209 & 176 & 149 \\
\hline & $\delta, \%$ & 2,1 & 4,3 & 11,4 & 5,5 & 8,8 & 15,8 \\
\hline \multirow{5}{*}{$\xi=1,49$} & $\sigma_{\mathrm{B}}, \mathrm{MПа}$ & 187 & 178 & 151 & 178 & 152 & 135 \\
\hline & $\delta, \%$ & 5,3 & 7,4 & 12,1 & 10,9 & 13,0 & 19,6 \\
\hline & & \multicolumn{6}{|c|}{ СЛиПП } \\
\hline & & \multicolumn{3}{|c|}{$T_{p a c n . n}=750^{\circ} \mathrm{C}$} & \multicolumn{3}{|c|}{$T_{\text {pacn } n}=780^{\circ} \mathrm{C}$} \\
\hline & & $\mu=16,8$ & $\mu=8,6$ & $\mu=5,2$ & $\mu=16,8$ & $\mu=8,6$ & $\mu=5,2$ \\
\hline \multirow{2}{*}{$\xi=0,74$} & $\sigma_{\mathrm{B}}, \mathrm{MПа}$ & 167 & 144 & 127 & 163 & 137 & 123 \\
\hline & $\delta, \%$ & 8,9 & 13,8 & 28,7 & 15,1 & 17,1 & 33,6 \\
\hline \multirow{2}{*}{$\xi=1,49$} & $\sigma_{\mathrm{B}}, \mathrm{MПа}$ & 162 & 142 & 122 & 160 & 120 & 111 \\
\hline & $\delta, \%$ & 10,6 & 18,4 & 29,7 & 15,6 & 21,6 & 34,0 \\
\hline
\end{tabular}

на валки, не превышают 170 кН при использовании метода СПП и 90 кН для метода СЛиПП. Усилия, действующие на матрицу, составляют 270 и 240 кН соответственно. Эти данные хорошо согласуются с результатами более ранних исследований [7], выполненных на лабораторной установке СПП-200 для сплавов системы Al-Ti-B. Повышенные значения усилия на матрице объясняются появлением незначительного «уса» из металла, формирующегося в зазоре между матрицей и валками и выдавливаемого ими.

На следующем этапе исследований проводилась оценка механических свойств полученных прутков. Для этого были проведены испытания образцов методом растяжения на универсальной испытательной электромеханической машине LFM400 усилием 400 кH с записью основных параметров процесса на ЭВМ. Основными величинами, определяемыми в опытах

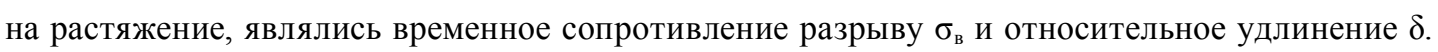
Результаты механических испытаний представлены в табл. 2.

Анализ полученных результатов показал, что прочностные свойства прутков, полученных методом СПП, выше, чем у прутков, полученных методом СЛиПП. Значения временного сопротивления разрыву прутков после совмещенной прокатки-прессования составляют от 135 до $215 \mathrm{MПа,} \mathrm{а} \mathrm{после} \mathrm{применения} \mathrm{совмещенного} \mathrm{литья} \mathrm{и} \mathrm{прокатки-прессования} \mathrm{от} 110$ до 170 МПа и варьируются в зависимости от температуры, скорости и степени деформации.

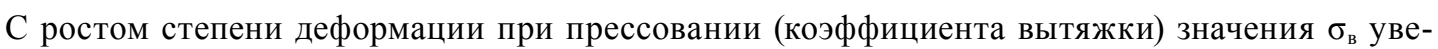
личиваются. Закономерности изменения временного сопротивления разрыву от скорости

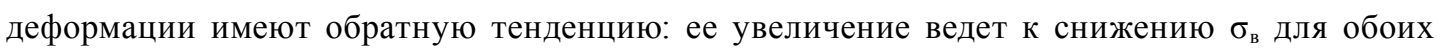
изучаемых процессов. В меньшей степени сказывается на прочностных свойствах изменение температуры заготовки (расплава). Однако снижение $\sigma_{\text {в }}$ сее увеличением также является установленной закономерностью. Пластические свойства прутков, полученных методом СЛиПП, выше по сравнению с методом СПП и максимальны для прутков диаметром 9 мм: 11-20 \% при СПП и 28-34 \% при СЛиПП. Закономерности изменения относительного удли-

$$
-651-
$$


нения следующие: с ростом степени деформации $\delta$ уменьшается, с ростом температуры и скорости деформации - увеличивается.

Проведенные испытания на разрыв подтвердили, что полученные лигатурные прутки обладают требуемыми прочностными и пластическими характеристиками для использования их в дозировочной машине непрерывной подачи лигатуры в расплав. Результаты исследования показали также, что реализация технологического процесса получения лигатурного прутка из сплавов Al-Ti-В с помощью совмещенных методов дает возможность повысить энергоэффективность производства и выход годного металла по сравнению с традиционными методами производства.

Для инженерной оценки обрабатываемости металла проводили холодное волочение полученных прутков и оценивали влияние степени деформации на механические свойства металла (рис. 3).

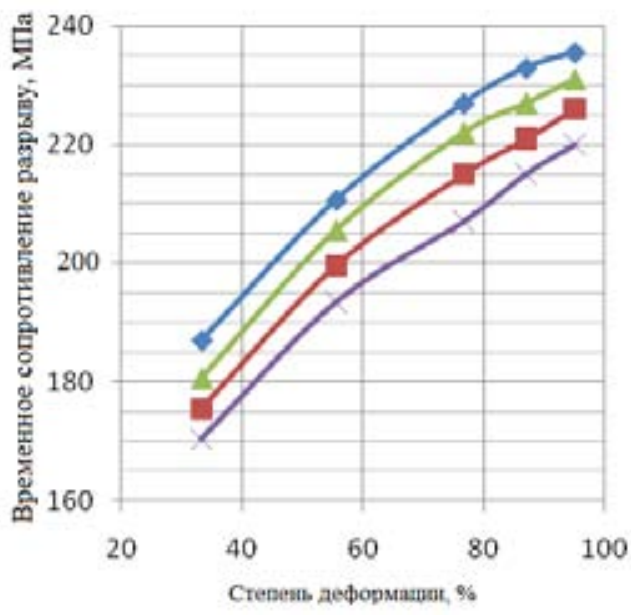

a

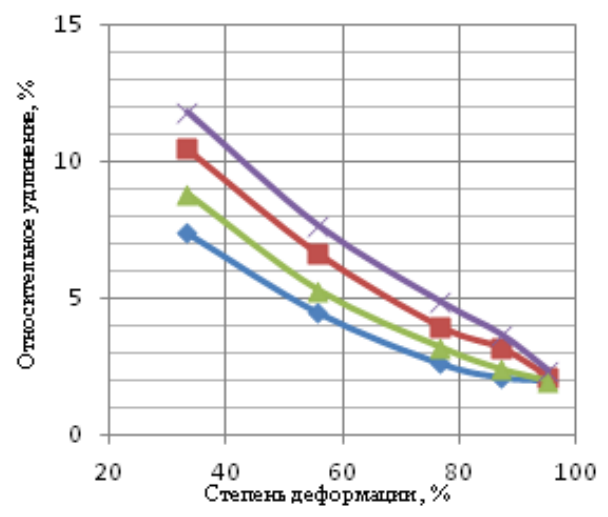

B

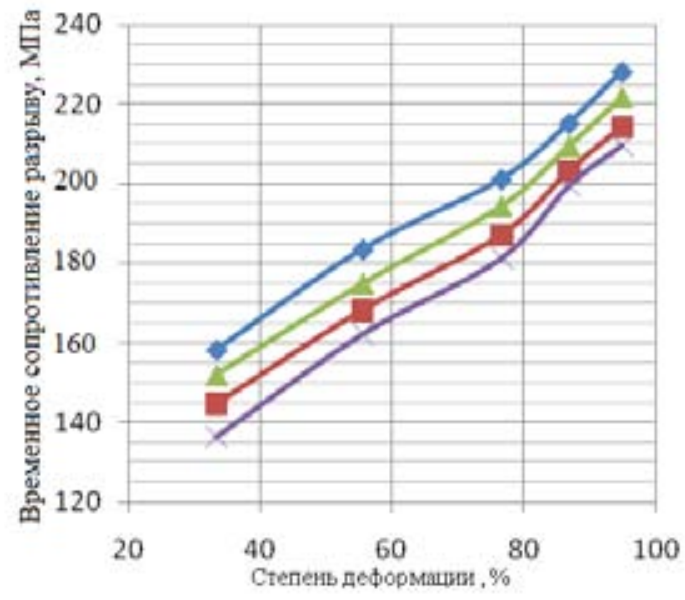

6

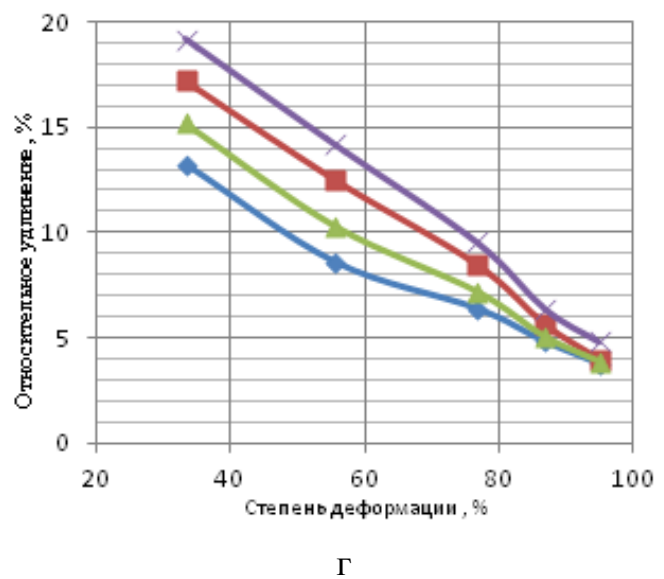

Рис. 3. Графики зависимости временного сопротивления разрыву (a, б) и относительного удлинения $($ в, г) от степени деформации для проволоки, изготовленной из прутков, полученных различными методами совмещенной обработки: а, в - СПП, $\diamond-T_{3}=550{ }^{\circ} \mathrm{C} \xi=0,74 \mathrm{c}^{-1}, \Delta-T_{3}=580{ }^{\circ} \mathrm{C} \xi=0,74 \mathrm{c}^{-1}, \square-$ $T_{3}=550{ }^{\circ} \mathrm{C} \xi=1,49 \mathrm{c}^{-1}, \times-T_{3}=580{ }^{\circ} \mathrm{C} \xi=1,49 \mathrm{c}^{-1} ;$ б, Г- СлиПП, $\diamond-T_{3}=750{ }^{\circ} \mathrm{C} \xi=0,74 \mathrm{c}^{-1}, \Delta-T_{3}=780{ }^{\circ} \mathrm{C} \xi=0,74 \mathrm{c}^{-1}$, $\square-T_{3}=750{ }^{\circ} \mathrm{C} \xi=1,49 \mathrm{c}^{-1}, \times-T_{3}=780{ }^{\circ} \mathrm{C} \xi=1,49 \mathrm{c}^{-1}$ 
В результате проведения исследований установлено, что полученные по различным методам деформированные полуфабрикаты в виде прутков могут подвергаться холодной деформации со степенями 95 \%, при этом не наблюдается обрывов проволоки и не требуется промежуточных отжигов. Прочностные характеристики при такой обработке достигают 230-240 МПа, а относительное удлинение падает до величин 2-4 \%. Пластические характеристики выше у прутков, полученных методом СЛиПП, поэтому и технологичность их обработки выше.

Металлографический анализ проводили на образцах после шлифования, полировки, травления и исследовали полученную микроструктуру на микроскопе OBSERVER.D1 фирмы Zeiss, с выводом микроструктуры на экран монитора. Съемку вели кинокамерой, находящейся непосредственно на микроскопе. Анализ микроструктуры был проведен по полученным фотографиям и непосредственно по полученным изображениям структуры. Изображение микроструктуры образцов было внесено в память компьютера при помощи программы AxioVision. Изучение микроструктуры проводили при увеличении х100.

Металлографический анализ показал, что в литом образце (рис. 4a) структура дендритная $\alpha$-твердого раствора имеет вид белых (светлых) дендритов, по фону которых расположены включения (интерметаллиды) в виде отдельных скоплений, имеющих вид многогранников, причем большинство находится у поверхности, где они распределены разбросанно. На прутках диаметром 9 мм, полученных методом СПП (рис. 4б), хорошо видна неоднородность распределения модифицирующих добавок, причем на поверхности видны мелкие, достаточно равномерно распределенные включения, которые укрупняются по мере перехода от края образца к его центру. С увеличением скорости деформации включения выравниваются по величине и равномерно распределяются по сечению образцов.

Металлографический анализ прутков, полученных методом СЛиПП с режимом $\mathrm{T}=780^{\circ}$ и $\xi=1.49$ (рис. 4в), и проволоки, изготовленной из него (рис. 42), показал, что данный режим

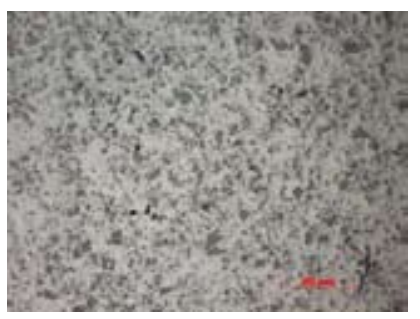

a

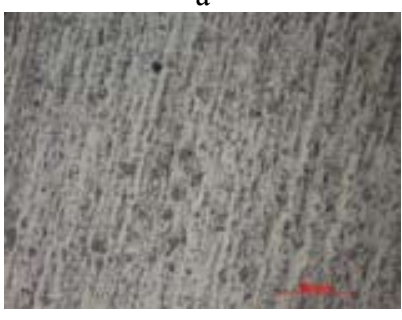

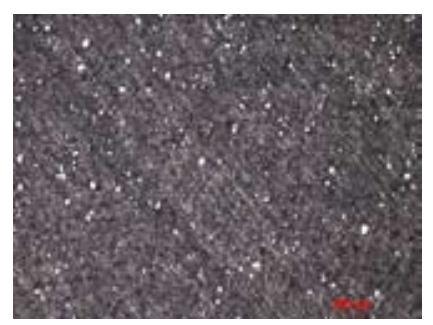

б

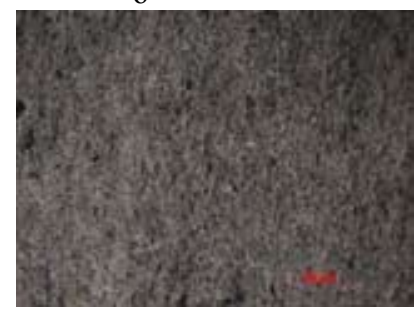

$\Gamma$

Рис. 4. Микроструктура литой заготовки (а), прутка диаметром 9 мм после СПП (б) при $\mathrm{T}=580{ }^{\circ} \mathrm{C}$ и $\xi=1,49 \mathrm{c}^{-1}$, прутка диаметром 9 мм после СЛиПП (в) при $\mathrm{T}=780{ }^{\circ} \mathrm{C}$ и $\xi=1,49 \mathrm{c}^{-1}$ и проволоки (г), полученной из этого прутка 
оптимален по расположению и величине интерметаллидных фаз. Частицы равномерно распределяются по сечению и являются дисперсными. С увеличением степени деформации у образцов хорошо прослеживается тенденция увеличения количества включений и повышение их дисперсности. Включения располагаются вдоль направления деформации, и им присуща округлая форма; особенно это характерно для более высоких скоростей деформации металла.

Таким образом, проведенные исследования дали возможность утверждать, что применение методов совмещенной обработки сплавов системы Al-Ti-B для изготовления лигатурных прутков не только выгодны с позиций энергосбережения, но и дают возможность повысить технологичность их обработки. Реализация новых технологий на основе применения совмещенных процессов СПП и СЛиПП позволит, таким образом, значительно снизить себестоимость лигатуры и добиться импортозамещения дефицитной и дорогостоящей продукции.

\section{Список литературы}

[1] Баузер М., Зауер Г., Зигерт К. Прессование: Справочное руководство: пер. с нем. М.: АЛЮСИЛ МВиТ, 2009. 918 с.

[2] Сидельников С.Б., Довженко Н.Н., Загиров Н.Н.. Комбинированные и совмещенные методы обработки цветных металлов и сплавов. М.: МАКС Пресс, 2005. 344 с.

[3] Сидельников С.Б., Беспалов В.М., Довженко Н.Н. и др. Пат. 138590 РФ / Б. И. 2014.

[4] Сидельников С.Б., Довженко Н.Н., Соколов Р.Е. и др. // Вестник МГТУ им. Г.И. Носова. 2009. № 4. C. 30.

[5] Довженко Н.Н., Сидельников С.Б., Беляев С.В. и др. Пат. 2486027 РФ (2012) / Б. И. 2013. № 18

[6] Орлов Г.А. // Известия вузов. Черная металлургия. 2013. № 3. С. 11.

[7] Сидельников С.Б., Галиев Р.И., Довженко Н.Н. // Известия вузов. Цветная металлургия. 2003. № 4. C. 49. 